\title{
Study of power management of standalone DC microgrids with battery supercapacitor hybrid energy storage system
}

\author{
Ali Gaeed Seger Al-Salloomee ${ }^{1}$, Saeed Khosroabadi ${ }^{1}$, Ali Abdulabbas Abdullah Albukariat ${ }^{2}$ \\ ${ }^{1}$ Department of Electrical Engineering, Imam Reza International University, Mashhad, Iran \\ ${ }^{2}$ Department of Electrical Engineering, Al-Furat Al-Awsat, Technical University, Babylon, Iraq
}

\begin{tabular}{l}
\hline Article Info \\
\hline Article history: \\
Received Jan 4, 2021 \\
Revised Jul 14, 2021 \\
Accepted Aug 12, 2021 \\
\hline
\end{tabular}

Keywords:

DC microgrids

Designed of standalone PV

system control

Hybrid energy storage system

Renewable energy

Smart grid

\begin{abstract}
In the last years, renewable energy (RE) is increasing widely in the energy sector, and microgrid technology is overgrowing. In this paper, stand-alone microgrid using solar photovoltaic (PV) energy as a source of renewable energy is simulated to provide power for direct current (DC) loads with hybrid energy storage system (HESS) which consists of battery and supercapacitor bank. The proposed microgrid system is tested under various cases of load and variable irradiance to confirm and validate the proposed management strategy to remain the DC bus voltage within a stable limit. The performance of DC microgrid is comparing with and without supercapacitor (SC) bank and notes a desirable decrease in the magnitude of transient voltage when using HESS. The sun power SPR-E19-320 standard was simulated to analyze system performance taking into account the constant load demand. Note that HESS helps reduce transient of DC voltage very effectively in all situations. Very large transients arise due to sudden changes in load demand is also compensated by HESS. The results obtained indicate that the stand-alone DC microgrid with HESS is very beneficial for reducing transient of DC-link voltage that occurs due to sudden change in load or fault. The proposed system is performed by MATLAB/Simulink environment.
\end{abstract}

This is an open access article under the CC BY-SA license.

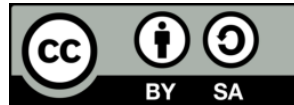

\section{Corresponding Author:}

Ali Gaeed Seger Al-Salloomee

Department of Electrical Engineering, Imam Reza International University

Mashhad, Iran

Email: aligaeed93@gmail.com

\section{INTRODUCTION}

The transition from the current energy system based on fossil fuels to a new system with implantation of renewable energy and electric transport systems requires the development of new control algorithms that allow managing the aspects related to both the intermittency and the distribution of the generation as well as the new consumption profiles [1], [2]. This leads to new challenges from the point of view of control [1], [3]. A microgrid can be considered as a set of loads, generators and storage that can be managed in isolation or connected to the rest of the electrical network coordinated to reliably supply electricity [4], [5]. Although it was originally associated with electrical networks, the concept has spread to any set of loads and generators that operate as a single controllable system that can provide both electrical energies as thermal and fuel to a certain area [6].

Today, the operation of energy resources distributed energy sources (DERs) along with controllable loads such as domestic consumption or electric vehicle and various forms of storage such as batteries, supercapacitors, or flywheels, constitute the central core of the microgrid concept [7]-[10]. Controlling microgrids presents numerous challenges, as that they can operate both in isolated mode and connected to the 
main network, through the point of common coupling (PCC) [11]-[14]. The system control must regulate frequency and voltage in any of the modes of operation, must distribute the load among the different distributed generations (DGs) and the storage, manage the flow with the network main and optimize operating costs [15]. The microgrid will switch to isolated mode in case of serious disturbances or failures and must then provide power to critical loads and the control system must in this case manage frequency and voltage [10]-[16]. In this paper, the direct current (DC) microgrid with hybrid storage elements which consists of battery bank and supper capacitor bank has been presented and analysis to overcome the transient issue and keep the output dc-link within acceptable limit under condition variations. The simulation result shows the proposed system is beneficial for mitigating the transient problem and the system is comparing with and without hybrid energy storage system (HESS) to confirm the effective the storage devices with microgrid.

\section{RESEARCH METHOD}

\subsection{Mathematical model of solar cell}

In order to determine the properties of the solar cell, curves of power versus voltage $(\mathrm{P}-\mathrm{V})$ and current versus voltage (I-V) must be created. The current is measured at the output when the cell is shortcircuited. From these curves, the maximum power point (MPP) can be checked. This model consists of photocurrent source, parallel diode, shunt resistance and series resistance. The single cell model was depicted in Figure 1 [17]-[22].

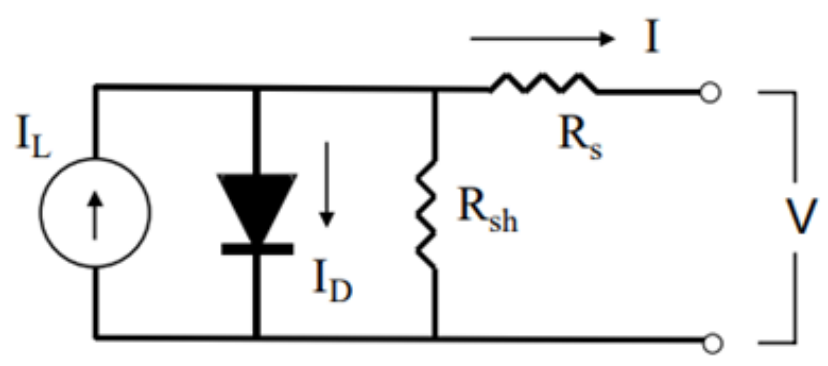

Figure 1. Simple ideal electrical circuit of solar cell

The analysis of the circuit in Figure 1 according to Kirchhoff's law, the output current can be written as in (1):

$$
\mathrm{I}=\mathrm{I}_{\mathrm{L}}-\mathrm{I}_{\mathrm{D}}-\mathrm{I}_{\mathrm{Sh}}
$$

The light current depends mainly on solar radiation and the cell's operating temperature, which are described as in (2):

$$
\mathrm{I}_{\mathrm{L}}=\frac{\mathrm{G}_{\mathrm{T}}}{\mathrm{G}_{\mathrm{T}, \mathrm{ref}}} \cdot\left(\mathrm{I}_{\mathrm{L}, \mathrm{ref}}+\mu_{\text {isc }} \cdot\left(\mathrm{T}_{\text {cell }}-\mathrm{T}_{\text {cell,ref }}\right)\right)
$$

The shunt current that runs through a parallel resistance is easily calculated according to the laws of the Kirchhoff circuit (3):

$$
\mathrm{I}_{\mathrm{sh}}=\frac{\mathrm{V}_{\text {cell }}+\mathrm{I}_{\text {cell }} \mathrm{R}_{\mathrm{s}}}{\mathrm{R}_{\mathrm{sh}}}
$$

The diode current is determined according to the equation of ideal Shockley diode, similar to (4):

$$
\mathrm{I}_{D}=\mathrm{I}_{\mathrm{O}}\left[\left(\exp \frac{\mathrm{v}_{\text {cell }}+\mathrm{I}_{\text {cell }} \mathrm{R}_{\mathrm{s}}}{V_{T}}\right)-1\right]
$$

where

$$
V_{T}=\frac{\mathrm{KT}}{\mathrm{q}}
$$


where constant of the electric charge on the electron with a standard uncertainty and the Boltzmann constant, according to the National Institute of Standards and Technology [21], are respectively $\mathrm{q}=1.602176 \mathrm{X}$ $10^{-19} \mathrm{C} \& \mathrm{~K}=1.38065 \mathrm{X} 10^{-23} \mathrm{~J} / \mathrm{K}$. The open circuit voltage can be calculated as (5),

$$
\mathrm{V}_{\mathrm{oc}}=V_{T} \cdot \ln \left[\frac{\mathrm{I}_{\mathrm{L}}}{\mathrm{I}_{\mathrm{o}}}\right]
$$

Generally, since we deal with a constant current, the output power of single cell can be depicted as (6):

$$
\mathrm{P}_{\text {cell }}=\mathrm{V}_{\text {cell }} \cdot \mathrm{I}_{\text {cell }}
$$

Therefore, the total power of array PV can calculate as (7):

$$
\mathrm{P}_{\text {tot }}=\mathrm{N}_{\mathrm{s}} \cdot \mathrm{V}_{\text {cell }} \cdot \mathrm{I}_{\text {cell }}
$$

The photovoltaic measure of performance is defined as the ratio of electrical energy produced during a solar incident (GT is solar radiation) and the efficiency of single cell can be expressed as (8):

$$
\eta=\frac{P_{\text {cell }}}{\mathrm{A}_{\text {cell }} \cdot G_{T}}
$$

\subsection{Maximum power point tracking (MPPT)}

MPPT is one of the essential components in the DC microgrid and also in a hybrid system based on renewable energy resources. There are two widely fundamental types used to provide high performance for following and tracking the maximum power, which are called perturb and observe (P\&O) MPPT and incremental conductance (INC) MPPT [17]. Figure 2 exposes the PV Panel block diagram with MPPT depends on the control mechanism. The value of the slope is negative [22]-[25]. The mathematically of these cases can be expressed as (9):

$$
\frac{\mathrm{dP}}{d V}=\left\{\begin{array}{cc}
>0 & V<V_{m p p} \\
=0 & V=V_{m p p} \\
<0 & V>V_{m p p}
\end{array}\right.
$$

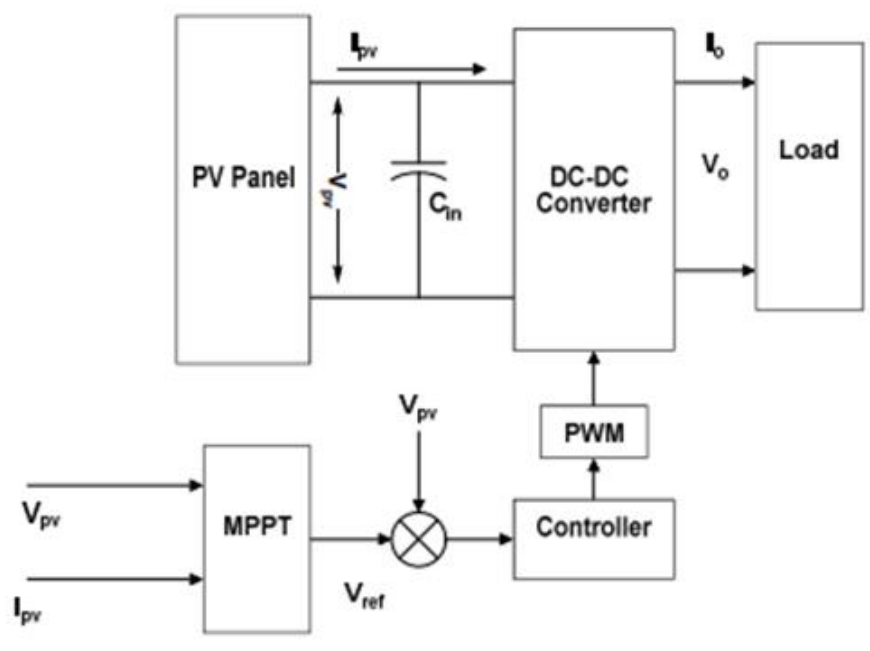

Figure 2. Standalone system with MPPT

Figure 3 depicts the algorithm of MPPT (P\&O). The first step of this algorithm measured the voltage and current of the PV solar energy using sensors. After that, the energy can be calculated the power change (dP) can be calculated as the difference between the current capacity and the previous power and also, the voltage change $(\mathrm{dV})$ can be calculated as the difference between the current voltage and the previous voltage. MPPT efficiency is calculated from (10). 


$$
\eta_{m p p t}=\frac{\mathrm{P}_{\mathrm{pv}}}{\mathrm{P}_{\mathrm{mppt}}} x 100
$$

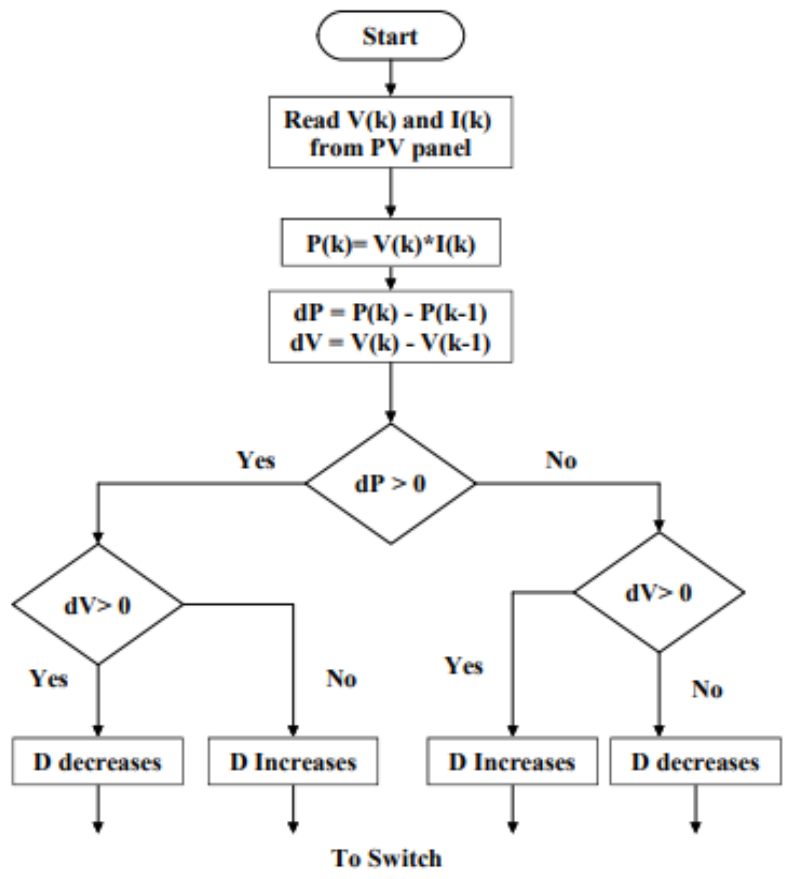

Figure 3. Flow chart of P\&O MPPT algorithm

\subsection{DC-DC converter}

In general, sustainable energy sources produce a low voltage at the output side. In order to connect this resource with the high voltage utility grid, we need to step up this voltage and inverted to AC by inverter device. For this intention, the step-up DC-DC converter is required [24]. In this paper, the boost converter is using due to it can be become as cascaded, which it enables to lift the voltage by the power of (n).

\subsubsection{Boost converter}

The boost converter is providing the output voltage is larger than the input voltage. It consists of two storage elements, inductor, and capacitor, and two electronics switching, diode and metal oxide semiconductor field effect transistor (MOSFET), as shown in Figure 4. The capacitor, inductor and capacitor, and two electronics switching, diode and MOSFET, as shown in Figure 4. The capacitor is used to remove or reduce the output voltage ripple, and the inductor is used to reduce the input current ripple. At the meanwhile, both of these elements are used to store energy to lift the output voltage.

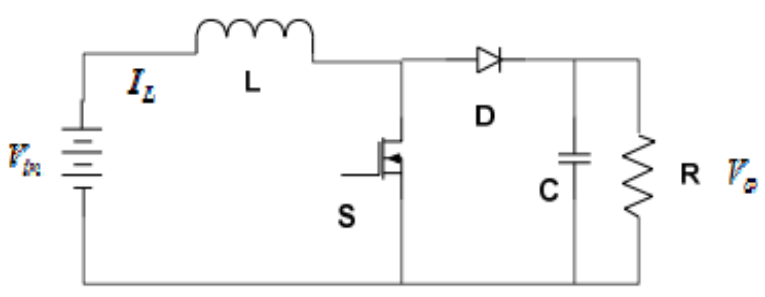

Figure 4. Boost converter circuit

According to the switched mode that explanation above, the output voltage of the boost converter is in (11):

$$
\mathrm{V}_{\mathrm{o}}=\frac{V_{\text {in }}}{1-d}
$$


For the cascaded boost converter, the above circuit in Figure 2 is considering as the first stage, and repetition this stage the output formula is increased by one power i.e., if the above circuit is repeated by one step the (11) is increased by two power $(n=2)$ and so on. The (11) can be rewritten as (12):

$$
\mathrm{V}_{\mathrm{o}}=\left(\frac{V_{\text {in }}}{1-d}\right)^{n}
$$

In order to design the inductor $\mathrm{L}$ and capacitor $\mathrm{C}$, we assume the maximum allowable ripple of the inductor current, maximum allowable ripple of the output voltage, and the switching frequency $\mathrm{f}$. the inductor and capacitor values can be designed as (13), (14):

$$
\begin{aligned}
& \mathrm{L}=\frac{V_{\text {in }} D}{f \Delta i_{L}} \\
& C=\frac{I_{o} D}{f \Delta v_{c}}
\end{aligned}
$$

\subsection{Supercapacitor bank}

The transient issue arising in the system due to sudden change in load or fault occurs of rapid change in PV power due to weather conditions cannot solve by only battery bank because of it has slow discharge characteristics. The supercapacitor has solved this issue due to having high power density [20], [23], [25]. The ratio of the total energy $\left(\mathrm{Q}_{c}\right)$ to the rated energy $\left(\mathrm{Q}_{0}\right)$ is called state of charge SOC\% and it can be calculated as (15),

$$
S O C=\frac{Q_{C}}{Q_{o}}=\frac{\frac{C \cdot V_{C}{ }^{2}}{2}}{\frac{C \cdot V_{\max }{ }^{2}}{2}}
$$

In order to charge and discharge of the supercapacitor (SC), the bidirectional DC-DC converter is used of this task and it is similar to that used in the battery bank. To save the lifetime of SC bank, it is discharged only until $20 \%$ of its $\%$ SOC.

\section{SIMULATION RESULTS}

To validate the DC microgrid with a hybrid storage device and to make the simulation results more realistic, the proposed scheme is tested under various conditions (variable load and irradiance). Sun power SPR-E19-320 has been used in this paper due to having excellent specifications. 9 numbers of 320-watt panels were used to form a micro grid. 4 of these panels are connected in series to form a chain, and 5 chains connected in parallel to complete the array system. The total power produced by this group is $6.8 \mathrm{Kw}$ at $1000 \mathrm{~W} / \mathrm{m} 2$ and $25 \mathrm{C} 0$. Table 1 shows the main parameters of this type used in MATLAB/Simulink in order to extract I-V properties. The test system is implemented in two situations.

Table 1. Specification parameters of SunPower SPR-E19-320

\begin{tabular}{ccc}
\hline Name & Symbol & Value \\
\hline Rated Power & Pmax & $320 \mathrm{~W}$ \\
Rated Voltage & Vmpp & $54.7 \mathrm{~V}$ \\
Rated Current & Impp & $5.86 \mathrm{~A}$ \\
Open Circuit Voltage & Voc & $64.8 \mathrm{~V}$ \\
Short Circuit Current & Isc & $6.24 \mathrm{~A}$ \\
Maximum System Voltage & VL & $600 \mathrm{~V}$ \\
NOCT & & $45^{\circ} \mathrm{C}+/-2^{\circ} \mathrm{C}$ \\
Series Fuse Rating & & $15 \mathrm{~A}$ \\
\hline
\end{tabular}

Case 1: In this case, the irradiance is changed as shown in Figure 5 and characteristics of PV as shown in Figure 6 and the output load is constant at $4 \mathrm{~kW}$. Figure 6 shows the steps of changing the irradiance with respect to time for the $\mathrm{P} \& \mathrm{O}$ test in the maximum power trace. The Figures 7(a) and 7(b) show the energy produced by the cells, the load energy, and the work of the storage part in the different phases of radiation. Figure 8 shows the output power of PV with load power and the properties of I-V and P-V under the change of radiation steps. It can be seen that when the output power of PV larger than the demand power, 
the battery bank is charged but when the output power of PV smaller than demand power due to irradiance variations, the battery bank is converted to discharge mode in fast response and the system is remained in stable limit and transient issue is very smaller and quickly die out to return the system to the steady state performance. The supercapacitor is very effective to help the battery bank to change from charge mode to discharge mode with very little bit of transient. In addition, the output DC voltage of PV is very stable and rapid reach to desire value as shown in Figure 9.

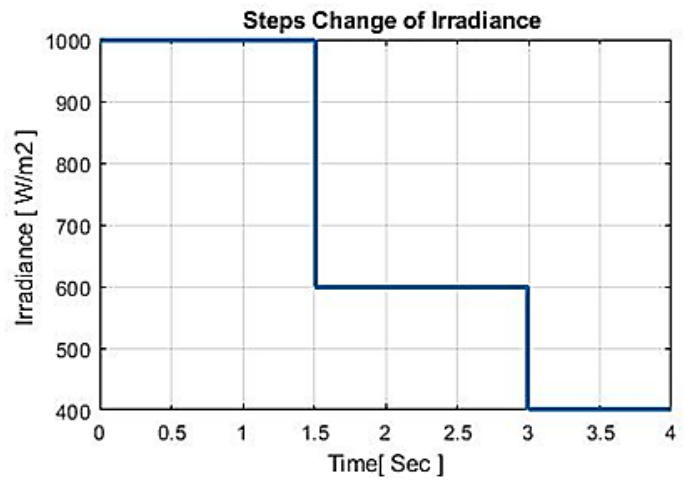

Figure 5. Steps change of irradiance

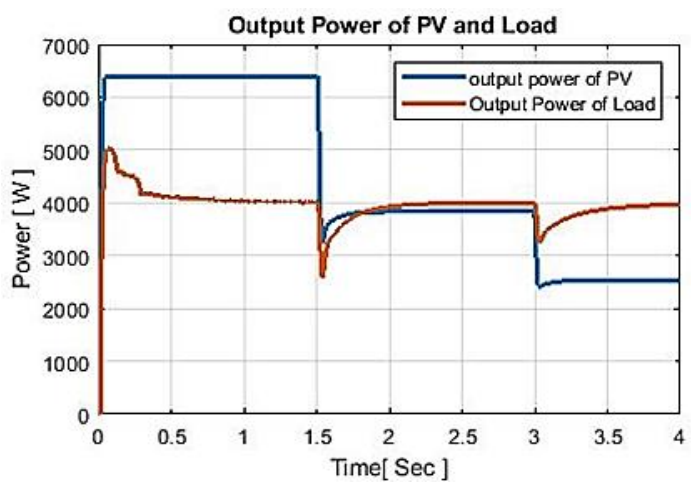

(a)
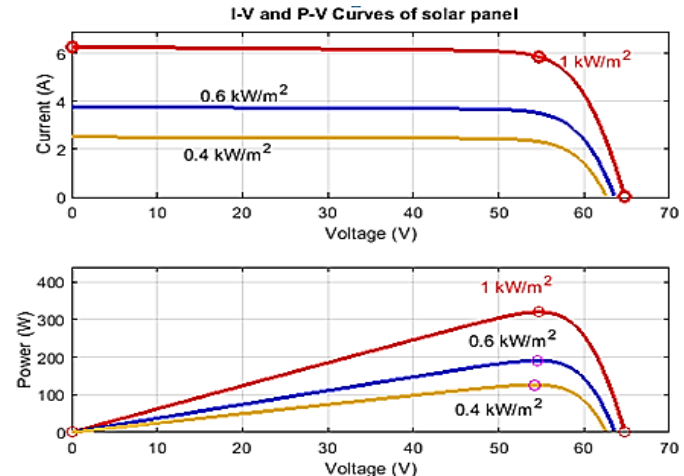

Figure 6. Characteristics of PV pane

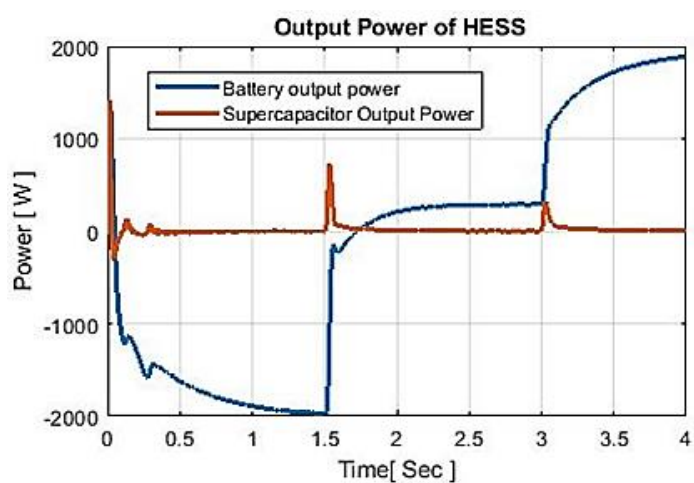

(b)

Figure 7. Performance of proposed system; (a) power variations of load and PV, (b) battery power and SC power variation

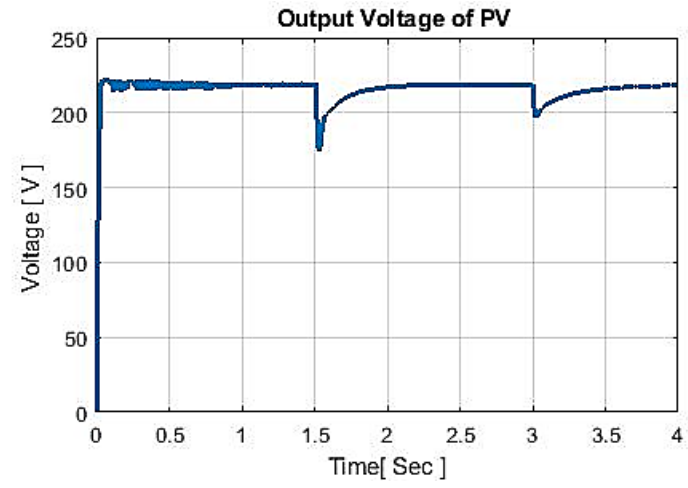

Figure 8. Voltage waveform of PV

Case 2: In this case, the irradiance is constant at $1000 \mathrm{~W} / \mathrm{m}^{2}$ and the output load is changed from $6 \mathrm{Kw}$ to $8 \mathrm{Kw}$ at $1 \mathrm{sec}$ as shown in Figure 9(a). It can see that the output power of battery is changed from charge mode to discharge mode at $1 \mathrm{Sec}$ as shown in Figure 9(a) because of the output power of PV does not 
enough to coverage the demand power. While Figure 9(b) exposed the power of supercapacitor and battery. It observes that the supercapacitor is helping the battery bank at moment of change in load and suppression the transient issue. The DC link voltage of PV is remaining in acceptable limit even though the change in load is large as shown in Figure 10.

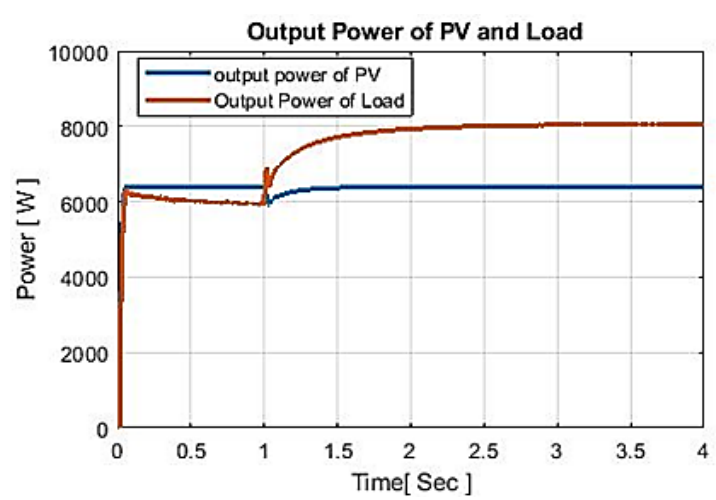

(a)

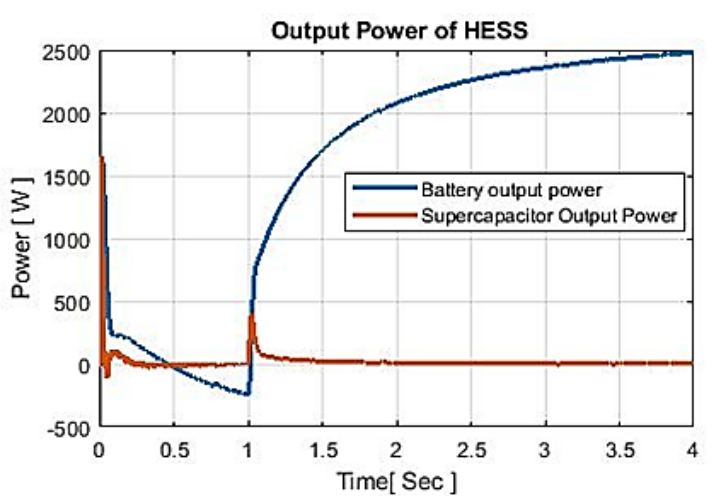

(b)

Figure 9. Performance of proposed system; (a) power variations of load and PV, (b) battery power and SC power variations

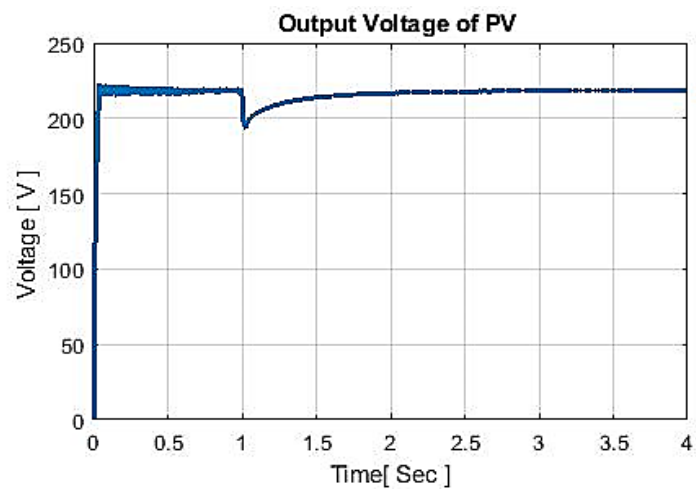

Figure 10. Voltage waveform of PV

\section{CONCLUSION}

This paper suggests and tests a stand-alone energy management strategy DC microgrid with PV source system and hybrid storage devises to maintain the DC-link voltage through various simulation case within stable limit as well as to reduce the transient oscillation that occurs due to sudden change in load or fault. Real solar sun data is used to validate the proposal strategy under irradiance variations. The simulation results show the proposed scheme with HESS is very beneficial for reducing the transient oscillation and keep the output DC link with stable limit.

\section{REFERENCES}

[1] C. Ndukwe, M. T. Iqbal, X. Liang, J. Khan, and L. Aghenta, "LoRa-based communication system for data transfer in microgrids," AIMS Electronics and Electrical Engineering, vol. 4, no. 3, pp. 303-325, 2020, doi: 10.3934/ElectrEng.2020.3.303.

[2] M. Khalid, "A review on the selected applications of battery-supercapacitor hybrid energy storage systems for microgrids," Energies, vol. 12, no. 23, p. 4559, 2019, doi: 10.3390/en12234559.

[3] C. Ghenai and M. Bettayeb, "Modelling and performance analysis of a stand-alone hybrid solar PV/fuel cell/diesel generator power system for university building," Energy, vol. 171, pp. 180-189, 2019, doi: 10.1016/j.energy.2019.01.019.

[4] R. H. Lasseter, "MicroGrids," 2002 IEEE Power Engineering Society Winter Meeting. Conference Proceedings (Cat. No.02CH37309), New York, NY, USA, 2002, vol. 1, pp. 305-308, doi: 10.1109/PESW.2002.985003.

[5] S. Choudhury, "A comprehensive review on issues, investigations, control and protection trends, technical challenges, and future directions for Microgrid technology," International transactions on Electrical Energy Systems, vol. 30, no. 9, Apr. 2020, doi: $10.1002 / 2050-7038.12446$. 
[6] G. V. B. Kumar and K. Palanisamy, "A review on microgrids with distributed energy resources," 2019 Innovations in Power and Advanced Computing Technologies (i-PACT), 2019, pp. 1-6, doi: 10.1109/i-PACT44901.2019.8960189.

[7] K. Sayed, A. G. Abo-Khalil, and A. S. Alghamdi, "Optimum resilient operation and control DC microgrid based electric vehicles charging station powered by renewable energy sources," Energies, vol. 12, no. 22, p. 4240, 2019, doi: 10.3390/en12224240.

[8] C. Huang, S. Weng, D. Yue, S. Deng, J. Xie, and H. Ge, "Distributed cooperative control of energy storage units in microgrid based on multi-agent consensus method," Electric Power Systems Research, vol. 147, pp. 213-223, 2017, doi: 10.1016/j.epsr.2017.02.029.

[9] D. Kumar, F. Zare, and A. Ghosh, "DC microgrid technology: system architectures, AC Grid interfaces, grounding schemes, power quality, communication networks, applications, and standardizations aspects," in IEEE Access, vol. 5, pp. 12230-12256, 2017, doi: 10.1109/ACCESS.2017.2705914.

[10] S. Dsilva, M. Shadmand, S. Bayhan, and H. Abu-Rub, "Towards grid of microgrids: seamless transition between grid-connected and islanded modes of operation," IEEE Open Journal of the Industrial Electronics Society, vol. 1, pp. 66-81, 2020, doi: 10.1109/ojies.2020.2988618.

[11] J. Hou and Z. Song, "A hierarchical energy management strategy for hybrid energy storage via vehicle-to-cloud connectivity," Applied Energy, vol. 257, 2020, doi: 10.1016/j.apenergy.2019.113900.

[12] B. Sahoo, S. K. Routray, and P. K. Rout, “AC, DC, and hybrid control strategies for smart microgrid application: A review," International Transactions on Electrical Energy Systems, vol. 31, no. 1, 2020, doi: 10.1002/2050-7038.12683.

[13] A. Hirsch, Y. Parag, and J. Guerrero, "Microgrids: A review of technologies, key drivers, and outstanding issues," Renew. Sustain. Energy Rev., vol. 90, pp. 402-411, Apr. 2018, doi: 10.1016/j.rser.2018.03.040.

[14] U. N. Ekanayake and U. S. Navaratne, "A survey on microgrid control techniques in islanded mode," Journal of Electrical and Computer Engineering, vol. 2020, pp. 1-8, 2020, doi: 10.1155/2020/6275460.

[15] N. Qachchachi, H. Mahmoudi, and A. El Hassnaoui, "Control strategy of hybrid AC/DC microgrid in standalone mode," International Journal of Renewable Energy Development, vol. 9, no. 2, pp. 295-301, 2020, doi: 10.14710/ijred.9.2.295-301.

[16] B. Liang et al., "Coordination control of hybrid AC/DC microgrid," The Journal of Engineering, vol. 2019, no. 16, pp. 3264-3269, 2018, doi: 10.1049/joe.2018.8505.

[17] T. S. Tran, D. T. Nguyen, and G. Fujita, "The analysis of technical trend in islanding operation, harmonic distortion, stabilizing frequency, and voltage of islanded entities," Resources, vol. 8, no. 1, 2019, doi: 10.3390/resources8010014.

[18] L. Ortiz, R. Orizondo, A. Aguila, J. W. Gonz, G. J. Lopez, and I. Isaac, "Hybrid AC/DC microgrid test system simulation: gridconnected mode," Heliyon, vol. 5, no. 12, 2019, doi: 10.1016/j.heliyon.2019.e02862.

[19] P. Haidl, A. Buchroithner, B. Schweighofer, M. Bader, and H. Wegleiter, "Lifetime analysis of energy storage systems for sustainable transportation," Sustainability, vol. 11, no. 23, p. 6731, 2019. doi: 10.3390/su11236731.

[20] Q. Xun, Y. Liu, and N. Zhao, "Energy efficiency comparison of hybrid powertrain systems for fuel-cell-based electric vehicles," 2020 IEEE Transportation Electrification Conference \& Expo (ITEC), pp. 1234-1239, 2020, doi: 10.1109/itec48692.2020.9161586.

[21] C. S. Balasubrahmanyam and O. H. Gupta, "Detailed study of solar energy conversion system using boost converter-a new MPPT technique," Journal of The Institution of Engineers (India): Series B, vol. 101, pp. 631-639, 2020, doi: 10.1007/s40031-02000478-1.

[22] K. JM, S. M. S., T. P. I. Ahamed, and M. Shafeeque, "Design and simulation of stand-alone DC microgrid with energy storage system," 2019 IEEE International Conference on Intelligent Techniques in Control, Optimization and Signal Processing (INCOS), 2019, pp. 1-5, doi: 10.1109/incos45849.2019.8951384.

[23] F. Nadeem, S. M. S. Hussain, P. K. Tiwari, A. K. Goswami, and T. S. Ustun, "Comparative review of energy storage systems, their roles, and impacts on future power systems," in IEEE Access, vol. 7, pp. 4555-4585, 2019, doi: 10.1109/ACCESS.2018.2888497.

[24] L. Ortiz, L. B. Gutiérrez, J. W. González, and A. Águila, "A novel strategy for dynamic identification in AC/DC microgrids based on ARX and Petri Nets," Heliyon, vol. 6, no. 3, 2020, doi: 10.1016/j.heliyon.2020.e03559.

[25] G. V. B. Kumar, P. Kaliannan, S. Padmanaban, J. B. Holm-Nielsen, and F. Blaabjerg, "Effective management system for solar PV using real-time data with hybrid energy storage system," Applied Sciences, vol. 10, no. 3, 2020, doi: 10.3390/app10031108. 